\title{
Aplicações de conceitos da mecânica em chutes de taekwondo
}

O Taekwondo é uma arte marcial milenar e, oficialmente, desde o ano 2000, está incluído no programa olímpico. O TKD, como também é conhecido, é um esporte que apresenta muito dinamismo em seus golpes, o que possibilita a existência de análises com a utilização da Física. Sendo assim, este trabalho teve como objetivo utilizar conceitos da mecânica na análise de golpes executados na modalidade esportiva Taekwondo, com o intuito de ser um auxílio nas práticas de ensino de Física no ensino médio. Utilizaram-se grandezas físicas como força, impulso, velocidade e momento angular na análise de quatro importantes chutes (ap tchagui, bandal tchagui, timio yop tchagui e mondolio tchagui). A linguagem e o formalismo, adotados na elaboração do texto, apresentam adequação em relação ao público-alvo.

Palavras-chave: Física do Taekwondo; Ensino de Física; Chutes de Taekwondo.

\section{Applications of mechanical concepts in taekwondo kicks}

Taekwondo is an ancient martial art and officially since 2000 has been included in the Olympic program. TKD, as it is also known, is a sport that presents a lot of dynamism in its blows, which allows the existence of analyzes using physics. Thus, this work aimed to use concepts of mechanics in the analysis of kicks performed in the sport Taekwondo, in order to be an aid in physics teaching practices in high school. Physical quantities such as force, impulse, velocity and angular momentum were used in the analysis of four important kicks (ap tchagui, bandal tchagui, timio yop tchagui and mondolio tchagui). The language and formalism, adopted in the writing of the text, are appropriate in relation to the target audience.

Keywords: Taekwondo Physics; Physics teaching; Taekwondo kicks.

Topic: Ensinos Multidisciplinares

Reviewed anonymously in the process of blind peer.
Received: 02/07/2019

Approved: 10/09/2019

Luis Philippe Arruda Lima (iD

Universidade Federal de Mato Grosso, Brasil

http://lattes.cnpq.br/7860864484969573

https://orcid.org/0000-0001-5906-0866

luisphilippe@fisica.ufmt.br

Kamyla Fernanda Silva Gama (it

Universidade Federal de Mato Grosso, Brasil

http://lattes.cnpq.br/2979113037580034

https://orcid.org/0000-0003-3244-9454

kamyllagama@hotmail.com

dete

DOI: 10.6008/CBPC2674-6654.2019.001.0001

\section{Referencing this:}

LIMA, L. P. A.; GAMA, K. F. S.. Aplicações de conceitos da mecânica em chutes de taekwondo. Humanum Sciences, v.1, n.1, p.1-6, 2019. DOI: http://doi.org/10.6008/CBPC 2674-6654.2019.002.0001 


\section{INTRODUÇÃO}

De origem coreana, o Taekwondo ("caminho dos pés e das mãos") é uma arte marcial milenar e é também uma modalidade esportiva olímpica, desde os Jogos Olímpicos de Verão realizados em Sidney (Austrália) no ano 2000, quando teve sua estreia oficial nos Jogos. A escolha do Taekwondo (TKD) como modalidade esportiva deve-se aos diversos benefícios que a arte propicia, como, por exemplo, a manutenção da saúde corpórea (PINTO e COSTA, 2016), devido ao elevado valor energético que a prática exige; e o bemestar social (PINHEIRO et al., 2015; FARIA et al., 2019), visto que TKD propicia, para os praticantes, sensações de competência e de diversão. Esses benefícios ofertados, bem como a maior divulgação do esporte por parte da mídia (principalmente no país tupiniquim), levaram o número de praticantes do TKD a uma ascendência, quando comparado com os números de praticantes, principalmente, das últimas décadas.

Os golpes do TKD exigem velocidade (ZAHRAN, 2010) e boa flexibilidade dos membros superiores e, principalmente, dos inferiores. Os golpes que utilizam os membros inferiores podem ser executados com as pernas estendidas ou flexionadas (com diferentes inclinações em relação à perna de apoio), podem ser giratórios (tanto com o ataque na altura do tronco quanto na altura da cabeça) e, em algumas situações específicas, os golpes podem ser executados com saltos (utilizando a parte lateral ou frontal do pé). Diante dessas dinâmicas existentes nas práticas dos golpes, alguns conceitos da mecânica podem ser utilizados na análise física desses movimentos. Esse interesse em analisar o movimento humano por meio de preceitos físicos-que é muito antigo, desde o tempo de Aristóteles (AMADIO e SERRÃO, 2011) -além de auxiliar na melhoria do rendimento esportivo dos atletas (biomecânica aplicada ao esporte) pode se tornar uma ferramenta útil nos contextos das práticas de ensino, pois se trata de exemplos práticos e que estão presentes no cotidiano dos alunos.

Diante desse contexto, este trabalho teve como objetivo utilizar conceitos físicos da mecânica na análise de golpes executados na modalidade Taekwondo, de modo a tornar este trabalho como sendo um auxílio nas práticas de ensino de Física para, em especial, o ensino médio.

\section{MATERIAL E MÉTODOS}

\section{Conceitos da mecânica}

Os conceitos físicos (mecânica) utilizados foram: aceleração; força; impulso; velocidade angular (movimento de rotação); e momento angular. Os golpes analisados utilizando os conceitos físicos foram: $A p$ tchagui: chute frontal com a perna flexionada (figura 1); Bandal tchagui: chute semicircular na altura do tronco (figura 2); Timio yop tchagui: chute lateral com salto, com "faca do pé" (figura 4); e Mondolio tchagui: chute com movimento circular, com extensão da perna, batendo com calcanhar ou prancha do pé (figura 5).

\section{RESULTADOS}

\section{Ap tchagui}


Tecnicamente, a execução do ap tchagui é simples. O primeiro movimento a ser executado é a elevação do joelho, mantendo-o flexionado (figura 1), e, posteriormente, o segundo movimento é estender a perna, em um movimento rápido (figura 1). Nessa situação pode ser verificado a importância da aceleração no golpe. Quanto maior for a variação da velocidade, maior será a aceleração do movimento e, por consequência, maior será a força aplicada.

Dessa forma, como a perna ainda está em repouso, então a força com que o golpe será executado dependerá apenas da velocidade final, isto é, dependerá da velocidade com que o golpe é desferido. Nesse caso, a força expressa, em módulo, conforme a segunda lei de Newton, será a equação $F_{A p}=\frac{m V_{f}}{\Delta t}$. Nessa expressão, $F_{A p}$ é a força aplicada pelo chute (em newton, N), m é a massa distribuída à perna que desfere o golpe (em quilograma, $\mathrm{kg}$ ), $V_{f}$ é a velocidade final na qual o chute é desferido (em metros por segundo, $\mathrm{m} \mathrm{s}$ $\left.{ }^{1}\right)$ e $\Delta t$ é o intervalo de tempo entre as ações de flexionar o joelho e desferir o chute (em segundo, s).

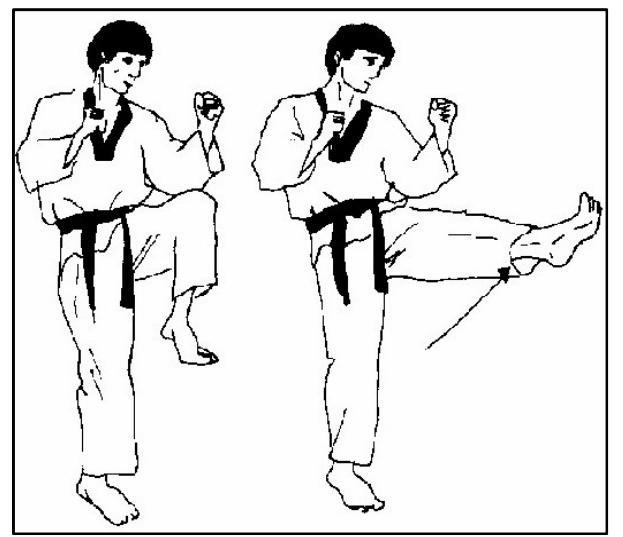

Figura 1: Representação do chute Ap tchagui.

\section{Bandal tchagui}

O bandal tchagui é um dos chutes mais utilizados em competições de TKD. O chute é uma combinação da flexão do joelho, flexão de quadril e rotação do tronco (por isso é semicircular). Para Pearson (1997), a fase inicial do chute é o momento em que, após sair do solo, a flexão do joelho é máxima, a fase de impacto é quando, com a pernada estendida, o alvo é atingido com o toque do pé e, por fim, a fase de recuperação é quando se finaliza o contato e, após isso, o pé retorna ao solo. As fases inicial e de impacto estão representadas pelos instantes B e C na figura 2. A rotação é um fator de suma importância para o êxito do chute. Sendo assim, esse chute pode ser utilizado como um exemplo clássico de movimento de rotação. O vetor posição do pé de apoio varia entre os instantes B $(\vec{r})$ e $C\left(\vec{r}^{\prime}\right)$, alcançando uma inclinação de até $120^{\circ}$ (figura 3), aproximadamente.

Considerando uma rotação de $120^{\circ}$ para o pé de apoio, a velocidade angular nessas condições, em módulo, pode ser definida conforme a equação $\omega=\frac{\Delta \varphi}{\Delta t}=\frac{2 \pi}{3 \Delta t}$. Nessa expressão, $\omega$ é a velocidade angular (em radiano por segundo, $\operatorname{rad~s}^{-1}$ ), $\Delta \varphi$ é o deslocamento angular do pé de apoio (em radiano, rad ), que foi substituído por $120^{\circ}$ convertido em radianos ( $\frac{2 \pi}{3}$ radianos), e $\Delta t$ é o intervalo de tempo, (em segundo, s), 
necessário para realizar o deslocamento angular de $120^{\circ}$. Quanto menor for o tempo maior será a velocidade angular e também maior será a possibilidade de pontuação, ao tocar o colete do oponente.

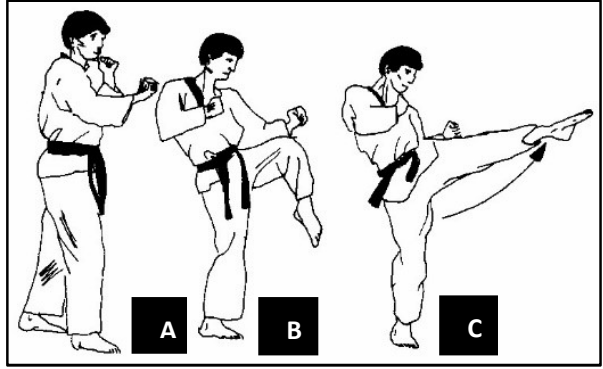

Figura 2: Representação do chute bandal tchagui.

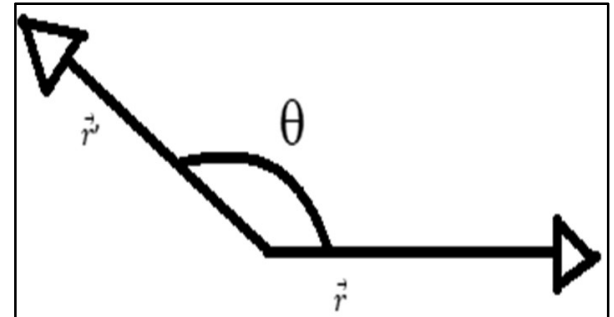

Figura 3: Ângulo $(\theta)$ formado com a rotação do pé de apoio entre as posições inicial e final, que estão representadas, respectivamente, pelos vetores $\vec{r}$ e $\vec{r}^{\prime}$

\section{Timio yop tchagui}

Um dos chutes mais admirados do TKD devido à beleza e ao seu poder de impacto, quando toca em algum oponente, é o Timio yop tchagui. A palavra Timio indica que o chute deve ser realizado por meio de um salto, que irá impulsioná-lo e, como consequência, aumentar a potência da execução. O Timio yop tchagui é o chute no qual se executa o yop tchagui, que é desferido de maneira lateral e com a sola do pé ("faca do pé"), com um salto. O primeiro momento do chute é aumentar a impulsão, aplicando força sobre o chão (figura 4), e, logo após, é saltar com a perna estendida lateralmente em direção ao oponente (figura 4).

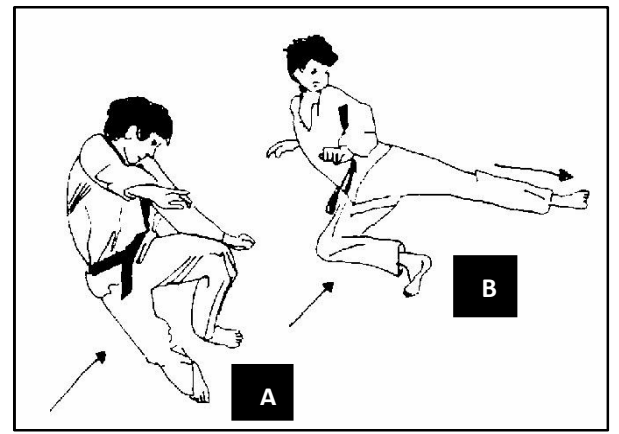

Figura 4: Representação do chute Timio yop tchagui.

Pode-se analisar o impulso de duas formas conforme os instantes A e B da figura 4 (início e fim da execução do chute, respectivamente): pela aplicação da força sobre o chão e pela variação da quantidade de movimento (ocasionada pelo salto). A expressão do impulso, em módulo, considerando a força aplicada sobre o chão pelo pé de apoio está na equação $I=F \Delta t$. Nessa expressão, l é o impulso adquirido (em newton vezes segundo, $\mathrm{N}$ s), F é a força aplicada sobre o chão pelo pé de apoio (em newton, N) e $\Delta t$ é o intervalo de tempo de aplicação da força (em segundo, s).

Em um caso hipotético cujo praticante, com massa de $70 \mathrm{~kg}$, aplica uma força igual a 1,5 vezes o seu peso, durante um intervalo de tempo de 1 segundo, o impulso adquirido por ele para execução do golpe será de $1029 \mathrm{~N}$ s. Obtém-se esse resultado ao substituir $F$, da equação anterior, pela força peso (P), que é definida como o produto da massa do praticante (em quilogramas, $\mathrm{kg}$ ) e a aceleração da gravidade (em metros por segundo ao quadrado, $\mathrm{m} \mathrm{s}^{-2}$ ), multiplicado por 1,5 (que é a proporção da força em relação ao peso do 
praticante) e por 1 (que é o tempo de aplicação da força em segundo). Na equação que segue, tem-se a adequação da equação que foi citada anteriormente. Propõe-se: $I=1,5 x(m g) x \Delta t$.

A outra forma de analisar é considerando a variação da quantidade de movimento, que é o produto entre a massa e a velocidade apresentada pelo corpo (em quilograma vezes metro por segundo, $\mathrm{kg} \mathrm{m} \mathrm{s}^{-1}$ ). Como a força também pode ser escrita como sendo a variação da quantidade de movimento $(\Delta Q)$, em relação ao tempo, o impulso em módulo pode também ser escrito conforme a equação $I=\frac{\Delta Q}{\Delta t} \Delta t$. Nessa expressão, ao simplificar $\Delta t$, o impulso será igual a variação da quantidade de movimento. Considerando que a massa do praticante não varia (entre início e fim do chute) e que a velocidade inicial é nula (no instante em que há aplicação da força sobre o solo), o impulso poderá também ser escrito como sendo o produto entre a massa do praticante e a velocidade final (antes de tocar o oponente).

\section{Mondolio tchagui}

O mondolio tchagui é um chute que exige um sincronismo entre o giro (figura 5) e o chute executado (com calcanhar ou sola do pé). Por isso, quando bem aplicado, costuma atingir uma grande potência. Não só o mondolio tchagui, mas todos os outros chutes que exigem um giro em torno do próprio eixo fazem com que o praticante, ao iniciar o movimento, adquira um momento angular (em quilograma vezes metro ao quadrado por segundo, $\mathrm{kg} \mathrm{m}^{2} \mathrm{~s}^{-1}$ ). Essa grandeza física pode ser definida como sendo o produto entre 0 momento de inércia do praticante (em quilograma vezes metro ao quadrado, $\mathrm{kg} \mathrm{m}^{2}$ ) e a velocidade angular (em radiano por segundo, $\mathrm{rad} \mathrm{s}^{-1}$ ).

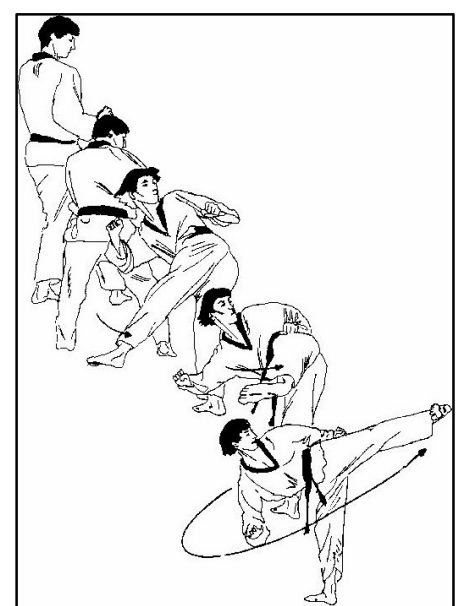

Figura 5: Representação do chute Mondolio tchagui.

\section{CONCLUSÕES}

O taekwondo é um esporte que apresenta uma alta dinâmica nas execuções dos golpes. Devido a isso, foi possível relacionar grandezas físicas (aceleração, força, impulso, velocidade angular e momento angular) com algumas das técnicas de chutes praticadas nessa arte marcial. Espera-se que este trabalho possa servir como um exemplo de aplicação prática desses temas, sendo uma possibilidade de recurso didático para as aulas de mecânica no ensino médio. 


\section{REFERÊNCIAS}

AMADIO, A. C.; SERRÃO, J. C.. A biomecânica em educação física e esporte. Revista Brasileira de Educação Física e Esporte, v.25, p.15-24, 2011. DOI:

https://doi.org/10.1590/S1807-55092011000500003

FARIA, L. O.; RIBEIRO, T. L.; SOUZA, T. F.; RENNÓ, G. V. C.; ALBUQUERQUE, M. R. Motivos para a prática de atividade física de esportes orientados à habilidade: um exemplo do Taekwondo. Revista Brasileira de Ciências do Esporte, v.41, n.2, p.198-205, 2019. DOI:

https://doi.org/10.1016/i.rbce.2018.10.004

PEARSON, J. N.. Kinematics and kinetics of the taekwondo turning kick. Monografia (Graduação em Educação Física) Universidade de Otago, Nova Zelândia, 1997.
PINHEIRO, M. F. G.; ANDRADE, A. G. P.; PINHEIRO, G. S.; NOCE, F.. Motivational dimensions of Taekwondo practitioners. Archives of Budo, v.11, p.401-409, 2015.

PINTO, S. A.; COSTA, G. C.. Motivação dos praticantes de Taekwondo: Estudo realizado em academias de Belo Horizonte. Revista Brasileira de Futsal e Futebol, v.7, n.27, p.495-504, 2016.

ZAHRAN, A. S. A.. Comparative study of some biological characteristics and posture deflections of the egyptian junior national taekwondo team. World Journal of Sport Sciences, v.3, p.1026-1033, 2010.

A CBPC - Companhia Brasileira de Produção Científica (CNPJ: 11.221.422/0001-03) detém os direitos materiais desta publicação. Os direitos referem-se à publicação do trabalho em qualquer parte do mundo, incluindo os direitos às renovações, expansões e disseminações da contribuição, bem como outros direitos subsidiários. Todos os trabalhos publicados eletronicamente poderão posteriormente ser publicados em coletâneas impressas sob coordenação da Sapientiae Publishing, da Companhia Brasileira de Produção Científica e seus parceiros autorizados. Os (as) autores (as) preservam os direitos autorais, mas não têm permissão para a publicação da contribuição em outro meio, impresso ou digital, em português ou em tradução. 